\title{
The Physical Activity Level in Female Affects Colon Transit Time
}

\author{
Jie-Hyun Kim \\ Department of Internal Medicine, Institute of Gastroenterology, Gangnam Severance Hospital, Yonsei University College of Medicine, Seoul, \\ Korea
}

Article: Colon transit time according to physical activity level in adults

Song BK, Cho KO, Jo YJ, Oh JW, Kim YS

(J Neurogastroenterol Motil 2012;18:64-69)

High levels of physical activity (PA) are associated with a reduced risk of some cancers, especially the colon cancer. One of the mechanisms proposed for the protective effect of $\mathrm{PA}$ on colon cancer is that colonic transit time (CTT) is decreased during exercising, which decreases the exposure to carcinogens, the concentration of bile acids and colonic segmentation. ${ }^{1,2}$ However, the effect may be dependent on the level of PA.

According to many studies, long-term aerobic training significantly protects against colonic carcinogenesis. ${ }^{3}$ Furthermore, the protective effects of $\mathrm{PA}$ on colonic carcinogenesis may depend on both the type of exercise and gender. ${ }^{3}$ According to experimental models, the number of large polyps in male $A p c^{\mathrm{Min} /+}$ mice was reduced after treadmill running, compared with controls, but these results were not observed in female mice. ${ }^{4}$ Although the biochemical and molecular processes underlying the interaction between PA and carcinogenesis are not well-understood, PA is known to generate reactive oxygen species to differing degrees. Mild oxidative stress caused by moderate PA can potentiate cellular antioxidant defense capacity by activating cellular stress response signaling. However, accumulation of rela- tively large amounts of reactive oxygen species as a consequence of exhaustive exercise or very high PA can directly damage DNA; this can cause mutation or promote carcinogenesis by activating proinflammatory signals. Although one of the mechanisms proposed for the protective effect of $\mathrm{PA}$ on colon cancer is that decreased CTT levels may reduce exposure to carcinogens, CTT itself is not a well-established risk factor for colonic neoplasm. ${ }^{1}$ The association between the risk of colorectal neoplasm and PA-induced reduction in CTT has not been investigated. ${ }^{2}$

However, analysis of CTT according to PA is one method of determining the mechanism underlying the protective effect of PA on colorectal neoplasm. Walking, running and strength training are known to reduce CTT. ${ }^{5-7}$ Also, a period of physical inactivity in subjects who had been engaged in regular PA for several years significantly increased CTT. ${ }^{8}$ However, some studies reported no effect of PA on CTT. ${ }^{9,10}$

Song et $\mathrm{al}^{11}$ in the present study investigated CTT according to physical activity level (PAL). The total CTT was significantly longer in female (25.8 hours) than male ( 7.4 hours) subjects. With regard to the dependence of the inter-group difference on

Received: December 7, 2011 Revised: None Accepted: December 12, 2011

(c) This is an Open Access article distributed under the terms of the Creative Commons Attribution Non-Commercial License (http://creativecommons. org/licenses/by-nc/3.0) which permits unrestricted non-commercial use, distribution, and reproduction in any medium, provided the original work is properly cited.

*Correspondence: Jie-Hyun Kim, MD

Department of Internal Medicine, Institute of Gastroenterology, Gangnam Severance Hospital, Yonsei University College of Medicine, 712 Eonju-ro, Gangnam-gu, Seoul 135-720, Korea

Tel: +82-2-2019-3505, Fax: +82-2-3463-3882, E-mail: otilia94@yuhs.ac

Financial support: None.

Conflicts of interest: None. 
PAL, the right CTT in female subjects was significantly shorter in the high PA group than in the moderate PA group, while there was no significant difference among male subjects. The recto-sigmoid CTT was significantly shorter in the high PA group than in the low PA group. Furthermore, there were significant differences in the total CTT between the low and moderate PA groups, and between the low and high groups of female subjects.

In this study, other factors associated with CTT, such as food intake, were not included. Thus, it is difficult to define the exact association between PAL and CTT based on these data alone. Furthermore, it is difficult to elucidate the differences in CTT according to PAL in males and females because of their different baseline CTT. The results can be interpreted to indicate that PAL affected CTT in subjects with a longer baseline CTT, but did not differ according to gender. In spite of these limitations, this study contributes to knowledge of the effect of PA on CTT.

In conclusion, this study contributes to a greater understanding of the relationship between PAL and CTT. According to results of this study, moderate and high PAL may assist colonic transit in females. A further study aiming to precisely define moderate and high PAL may assist in the determination of optimal exercise regimes.

\section{References}

1. Hardman AE. Physical activity and cancer risk. Proc Nutr Soc
2001;60:107-113

2. Harriss DJ, Cable NT, George K, Reilly T, Renehan AG, Haboubi $\mathrm{N}$. Physical activity before and after diagnosis of colorectal cancer: disease risk, clinical outcomes, response pathways and biomarkers. Sports Med 2007;37:947-960.

3. Na HK, Oliynyk S. Effects of physical activity on cancer prevention. Ann N Y Acad Sci 2011;1229:176-183.

4. Mehl KA, Davis JM, Clements JM, Berger FG, Pena MM, Carson JA. Decreased intestinal polyp multiplicity is related to exercise mode and gender in ApcMin/+ mice. J Appl Physiol 2005;98:2219-2225.

5. De Schryver AM, Keulemans YC, Peters HP, et al. Effects of regular physical activity on defecation pattern in middle-aged patients complaining of chronic constipation. Scand J Gastroenterol 2005;40: 422-429.

6. Oettlé GJ. Effect of moderate exercise on bowel habit. Gut 1991;32: 941-944.

7. Koffler KH, Menkes A, Redmond RA, Whitehead WE, Pratley RE, Hurley BF. Strength training accelerates gastrointestinal transit in middle-aged and older men. Med Sci Sports Exerc 1992;24:415419.

8. Liu F, Kondo T, Toda Y. Brief physical inactivity prolongs colonic transit time in elderly active men. Int J Sports Med 1993;14:465467.

9. Coenen C, Wegener M, Wedmann B, Schmidt G, Hoffmann S. Does physical exercise influence bowel transit time in healthy young men? Am J Gastroenterol 1992;87:292-295.

10. Roberts R, McKinley S, Brooks B, Ganley E, Hindle D. The Australian National Non-Acute Inpatient Project. Aust Health Rev 1993;16:300-319.

11. Song BK, Cho KO, Jo YJ, Oh JW, Kim YS. Colon transit time according to physical activity level in adults. J Neurogastroenterol Motil 2012;18:64-69. 